\title{
O corpo suturado: Interfaces sonoras e a construção das condições de audibilidade dos jogos digitais
}

\author{
The sutured body: sonic interfaces and the design of audibility layouts in \\ digital games
}

\section{Eduardo Harry Luersen}

Doutor em Ciências da Comunicação pela Universidade do Vale do Rio dos Sinos, com estágio de sanduíche realizado no Gamification Lab (Leuphana Universität Lüneburg). 0 texto é vinculado à pesquisa Ressonância tecnocultural: rastros da ambiência contemporânea nas sonoridades dos jogos digitais, recentemente concluída. A pesquisa recebeu o apoio de CNPq, Capes e DAAD.

\section{RESUMO}

A dimensão audível dos jogos digitais nos fala sobre a tecnocultura contemporânea e as reconfigurações na atual ecologia das mídias. Neste artigo propomos observar alguns destes rearranjos através de uma exploração tentativa das condições de interfaceamento estabelecidas pelos jogos digitais através do design sonoro. Por meio de uma abordagem mídia-arqueológica, observamos como os modos de organizar o material sonoro, sobretudo no design de jogos digitais em primeira e terceira pessoa, participam na criação dos seus mundos audiovisuais jogáveis. Iniciamos o texto com uma breve exploração conceitual do termo interface para, então, articularmos o design sonoro dos jogos com formatos audiovisuais pregressos. Em seguida, realizamos a análise dos modos particulares por meio dos quais computador e humano são interfaceados através do som nos jogos digitais, e conjeturamos como as interfaces tornam manifestas reconfigurações latentes na cultura contemporânea.

PALAVRAS-CHAVE: Design sonoro; Interfaces; Tecnocultura; Jogos digitais.

\section{ABSTRACT}

Dossiê Crise, Feminismo e Comunicação - https://revistaecopos.eco.ufrj.br/

ISSN 2175-8689 - v. 23, n. 3, 2020

DOI: $10.29146 /$ eco-pos.v23i3.27451 
The audible dimension of digital games informs us on contemporary technoculture and the reshaping of our current media ecology. In this article, we observe some of these rearrangements through a tentative probing of the interfacing conditions of gaming established by its sound design. Through a media-archaeological approach, we observe how sonic space is organized, especially in the design of digital games in first and third-person perspective, taking part in the construction of playable audiovisual environments. We begin the text with a brief examination of the concept of the interface, so that we can articulate the sound design of digital games with previous audiovisual formats. Then, we analyze the particular ways in which computers and humans are interfaced through sound in digital games, in order to estimate how interfaces manifest potential shifts in contemporary culture.

KEYWORDS: Sound design; Interfaces; Technoculture; Digital games.

\section{RESUMEN}

La dimensión audible de los juegos digitales nos hablan de la tecnocultura contemporánea y de las reconfiguraciones en la ecología de los medios actuales. En este artículo, proponemos observar algunas estas reorganizaciones mediante una exploración de las condiciones de interfaz establecidas por los juegos digitales a través del diseño de sonido. Por medio de un enfoque de la arqueología de los medios, observamos cómo las formas de organizar el material sonoro, especialmente en el diseño de juegos digitales en primera y tercera persona, participan en la creación de sus mundos audiovisuales y jugables. Comenzamos el texto con una breve exploración conceptual del término interfaz para luego articular el diseño de sonido de juegos con formatos audiovisuales anteriores. Luego, analizamos las formas particulares en que la computadora y el ser humano se interconectan a través del sonido en los juegos digitales, y conjeturamos cómo las interfaces se hacen manifiestas las reconfiguraciones latentes de la cultura contemporánea.

PALABRAS CLAVE: Diseño de sonido; Interfaces; Tecnocultura; Juegos digitales.

Cientes de que as sonoridades dos jogos digitais dizem muito sobre a tecnocultura, ao deporem sobre o modo como a atual ecologia dos meios vem reordenando o arranjo de forças e tendências que atravessam as modelagens estéticas do audiovisual contemporâneo, propomos neste artigo observar os jogos especificamente através do design de interfaces sonoras.

Dossiê Crise, Feminismo e Comunicação - https://revistaecopos.eco.ufrj.br/

ISSN 2175-8689 - v. 23, n. 3, 2020

DOI: 10.29146/eco-pos.v23i3.27451 
Iniciamos o trabalho com uma breve exploração do conceito de interface e observamos a sua articulação com formatos audiovisuais pregressos para, em seguida, realizarmos a análise de modos de interfaceamento entre computador e humano nos jogos digitais, através de sua dimensão audível. Por meio de uma abordagem mídia-arqueológica, podemos observar como tais modos de organizar o material sonoro, sobretudo no design de jogos digitais em primeira e terceira pessoa, participam na criação dos seus mundos audiovisuais jogáveis.

As interfaces sonoras, que estabelecem as condições materiais de experiência do jogo, nos mostram que estes modos de interfaceamento não são exclusivos aos games, enquanto artefatos técnicos culturais que partilham disposições estéticas e formas de organizar a experiência sensível com outros aparelhos de uma mais ampla ecologia dos meios. Em especial, interessa a este artigo observar como o arranjo destes sons, a partir de predefinições de design, deixa-nos entrever condições tecnoculturais de fundo que orientam determinadas qualidades sonoplásticas. Tais condições não apenas conectam as diversas formas, estéticas, hábitos e usos de mídias no cotidiano, sendo importantes para percebermos uma ecologia das mídias em curso, como também participam na conformação material de demais aparatos tecnoestéticos (audiovisuais e sonoros) da contemporaneidade. São aspectos que ligam as condições de uso das mídias digitais a elementos pontuais de uma mais larga história do design de interação humano-máquina. A seguir, procuramos desentranhar o papel particular das interfaces sonoras na ação de suturar humano e computador no design dos jogos digitais.

\section{Efeitos relacionais entre o design sonoro dos jogos digitais e a} tecnocultura

Propomos realizar aqui procedimentos da ordem de um resgate de interfaces (Fischer, 2012), como forma de apreender aspectos das sonoridades dos 
jogos digitais que os discursos recorrentemente "novidadeiros" sobre os jogos tendem a tornar opacos. Tais retóricas são reforçadas por uma historiografia cronologicamente linear contada sobre este meio (Guins, 2017; Huhtamo, 2005). Neste movimento, buscamos identificar traços genealógicos dos modos como os jogos constroem interfaces, enquanto precondições materiais para a experiência de seus mundos jogáveis através do som. Este gesto de resgate é orientado por uma disposição mídia-arqueológica, que se caracteriza pelo vasculhamento de arquivos textuais, visuais e sonoros, bem como pela coleção de artefatos, o que enfatiza tanto as expressões discursivas como as manifestações materiais da cultura, movendo-se flexivelmente entre as disciplinas (Huhtamo; Parikka, 2011, p.3).

Conforme aponta Erick Felinto (2011), tal disposição, quando combinada com uma atenção às materialidades das mídias, além de contestar os discursos triunfalistas, apocalípticos ou saudosistas que ocupam seguidamente os debates sobre mídia e tecnologia, também permite abrir o horizonte às heterocronias, aos saltos e às descontinuidades que acompanham a cultura das mídias. Assim, buscamos contribuir para desentranhar uma narrativa histórica muito facilmente calcificada em uma perspectiva estreita, centrada no jogo, na inovação e na invenção (Guins, 2014, p.2), para que seja possível reavaliar tais artefatos inserindo-os em uma malha tecnocultural mais larga.

Podemos iniciar, no âmbito conceitual, apresentando uma noção de interface que articule técnica e cultura para, em seguida, a mobilizarmos em direção às construções sonoras dos jogos digitais. No segundo capítulo de The Language of New Media (2001), Lev Manovich introduz o termo interfaces culturais para descrever as interfaces gráficas de usuários $^{1}$ de sites, aplicações de hipermídia, jogos digitais e outros "objetos culturais" disseminados através de um computador. A esta proposição é central que o computador seja entendido como uma máquina de mídia universal, capaz de manipular formatos predominantemente

\footnotetext{
${ }^{1}$ Do inglês GUI: graphical user interfaces.
}

Dossiê Crise, Feminismo e Comunicação - https://revistaecopos.eco.ufrj.br/ 
identificados com a produção cultural, como textos, fotos, filmes, canções, documentos, ambientes 3D, etc. Manovich (2001, p.69) sugere que, deste modo, o interfaceamento humano-computador pode ser melhor descrito como parte de uma mais ampla interface humano-computador-cultura, como uma interface cultural. Para ele, a linguagem de superfície apresentada pelas interfaces gráficas é mais facilmente compreendida pelos usuários em função da reminiscência de formatos familiares em sua aparência. Tais formatos permitem que percebamos as articulações e tensões entre a trajetória dos meios de representação - que deixam suas marcas nos materiais emergentes - e as propriedades computacionais cada vez mais presentes nas práticas culturais.

Manovich organiza estes apontamentos, sobretudo, a partir da análise de telas, tomando-as como espaços privilegiados para observar as composições visuais convergentes com os processos de computadorização da cultura (Fischer, 2013). Queremos propor aqui que os rastros destes processos podem ser analisados também a partir das construções sonoras de interfaces culturais, para além de seus aspectos visuais, ainda que esta tarefa conduza a outros desafios, decorrentes das propriedades de cada modalidade de expressão. Ao estancarmos o fluxo do filme, não temos mais um filme, é verdade, mas ainda nos resta ao menos um frame para analisar. Ao estancarmos o movimento do som, o que nos resta? Decorre como opção, a partir deste problema, explorarmos alternativas à noção de interface, como aparato material determinante no modo de produzir as sonoridades dos jogos, para em seguida cotejarmos como os modos de organizar a informação sonora se relacionam com as condições de interfaceamento do meio.

Consideremos as ponderações de Ian Bogost (2015) sobre a interface. 0 autor indica que o desenvolvimento histórico dos softwares enquanto ferramentas de trabalho fez com que as expectativas formais e estéticas quanto às interfaces humano-computador fossem, desde a sua concepção projetual, subordinadas aos seus aspectos funcionais. Um bom software, assim, seria aquele que mais eficientemente apresentasse o que se chama, no design de experiência do usuário 
(UX Design), de transparência: deveria mostrar como ser usado e cumprir de forma mais imediata às suas expectativas de uso. Bolter e Gromala (2003) sugerem que este conceito de transparência atrelado à interface é problemático, pois dá a entender que a interface de operação do software age como uma janela - como um operador neutro, que desaparece ao promover seu caráter funcional. Bogost (2015) sugere que esta concepção é especialmente problemática para se pensar em formas expressivas, afinal, um direcionamento meramente funcional retroalimenta a produção de interfaceamentos familiares, tolhendo as potências de diferenciação que outras formas de mediação poderiam atribuir aos projetos estéticos.

Efetivamente, no design de interfaces estão implicados modos particulares de construir formas de ver, ouvir e sentir os mundos audiovisuais, que estabelecem precondições de experiência a partir de seus modelos. Segundo Rafael Cardoso (2016, p.236), o design é uma disciplina projetual que atua na conformação material de artefatos, tangenciando outras áreas como a arquitetura, as artes plásticas e a engenharia, operando especialmente sobre instâncias de mediação entre os objetos materiais e as práticas sociais. Em particular, nos interessa aqui o modo como as materializações do design carregam em si rastros tanto de anseios declarados como de motivações silenciosas que conduzem à conformação material das interfaces. Em nosso caso, isto significa que o modo como o aparato dos jogos digitais é construído está imbuído de imaginários e de visões de mundo específicos que nele se cristalizam. Pela análise das suas interfaces sonoras, podemos colocar o problema da matéria, da sua constituição espacial, em uma perspectiva mais larga.

Outra entrada complementar, produtiva para tentarmos aproximar inicialmente os construtos sonoros dos jogos de uma noção sobre a interface, é a que Alexander Galloway propõe em The unworkable interface (2008, p.941). Segundo esta perspectiva, antes de tudo, a interface é um efeito de relação que produz coerência entre dois domínios que, sem ela, seriam incompatíveis. Em 
lugar das metáforas que comparam interfaces a janelas para um dado lugar, Galloway as define mais largamente como meios para comunicar entre espaços, conferindo-lhes um estatuto de limiar. Mais estritamente, no caso da dimensão audível dos games, podemos vislumbrar como o estabelecimento de uma interface se define pelo conjunto de técnicas e formas que operam na mediação da relação entre jogador e jogo. É o que exploraremos a seguir.

\section{Interfaces sonoras nos games e para além deles}

A partir da ideia da interface como produtora de efeitos de relação entre domínios, e em conjunção com nosso interesse mídia-arqueológico, poderíamos considerar o ambiente de experiência do cinema clássico, a sala de exibição, como uma interface - com todo o conjunto de técnicas que nela interpelam o espectador. Para José Cláudio Castanheira (2010, p.116), mesmo as experiências mais radicais dos videogames, videoclipes e manifestações híbridas de outras mídias, são devedoras em algum grau de uma gramática desenvolvida para os filmes. Podemos nos referir aqui, mais particularmente, ao aparato cinematográfico, pensando no gradual incremento de técnicas na sala de exibição para produzir um aparato imersivo mais eficaz. Ainda que os jogos digitais estimulem outros modos, tanto de atividade, quanto de passividade do corpo diante da obra - e que o tema da imersão tenha se tornado um clichê na teoria dos games - nos parece ainda subexplorada a relação que há entre o design sonoro dos jogos, a proposição de estímulos audíveis ao corpo, a exigência de atenção do jogador e as técnicas desenvolvidas para interfacear espectador e filme, através da disposição espacial da sala de exibição do cinema.

A ideia de imersão nos games é normalmente associada a uma presumida natureza do som, e este juízo do sonoro enquanto elemento essencialmente imersivo é reproduzido em discursos de senso comum sobre a experiência sensória cinematográfica, ideia que Sterne (2012, p.9) descreve como parte de uma 
litania do audiovisual. Efetivamente, na experiência do cinema o som é construído como tal, e os games alimentam-se dos efeitos de técnicas que estenderam esta característica, como o surround e o dolby (Figuras 1 e 2) - parte do projeto das audiovisões cinematográficas hiper-reais e dos construtos de espaço respectivos. Ainda antes, nos anos 1950, o próprio desenvolvimento da estereofonia veio a estimular a exploração de construtos imersivos - não naturais, portanto, mas naturalizados. 0 estéreo permitiu projetar ambientes sonoros baseados em modelos de escuta orientados, por sua vez, pela noção euclidiana de espaço tridimensional, de modo análogo a como a perspectiva aérea concebera modelos ópticos a partir da pintura.

Na figura abaixo, observamos uma imagem publicitária do sistema Dolby Atmos, que empregava uma determinada concepção de espaço acústico, desde a arquitetura da sala à distribuição de alto-falantes do sistema de reprodução sonora. Visando construir um espaço de potencial imersibilidade para o espectador, o sistema o posiciona relativamente centralizado com relação à direcionalidade do som no ambiente construído.

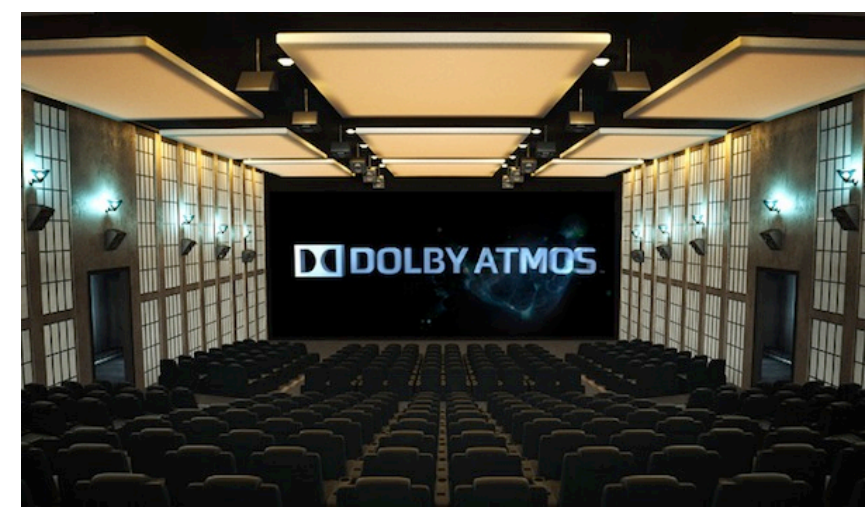

FIG. 1: Imagem publicitária do sistema Dolby Atmos. Fonte: Panorama audiovisual².

Já na figura abaixo, observamos a representação dos objetos sonoros construídos (à direita), e a distribuição das saídas de áudio na sala, em mapa

2 Odeon \& UCI Cinemas chooses Dolby Atmos to screen across Europe iSens. [S.l.], 2013. Disponível em: <https://www.panoramaaudiovisual.com/en/2013/06/24/odeon-uci-cinemas-elige-dolbyatmos-para-pantallas-isens-de-toda-europa/>. Acesso: 20 fev. 2020.

Dossiê Crise, Feminismo e Comunicação - https://revistaecopos.eco.ufri.br/

ISSN 2175-8689 - v. 23, n. 3, 2020

DOI: 10.29146/eco-pos.v23i3.27451 
planificado (à esquerda), visando precisar a localização espacial dos eventos sonoros representados.

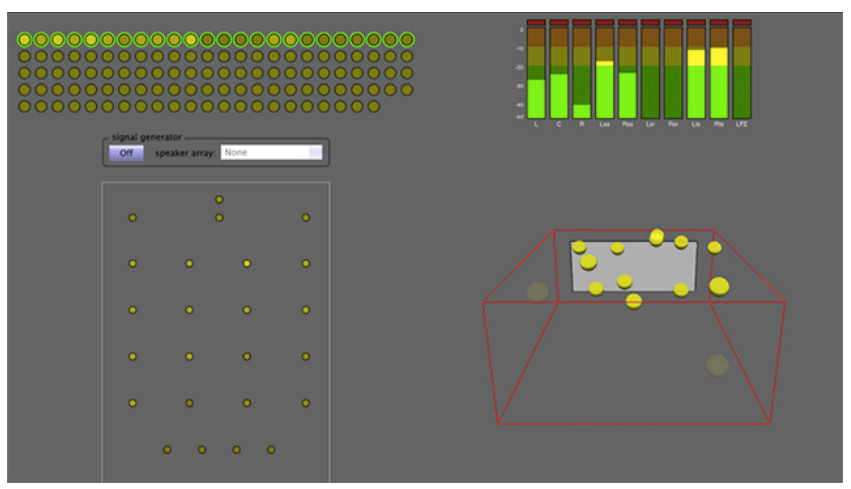

Figura 2: Software de monitoramento do sistema Dolby Atmos. Fonte: Remote West ${ }^{3}$.

Um tipo de arranjo espacial análogo a este é previamente incorporado a muitos motores de implementação de áudio nos jogos. Para localizar eventos sonoros no mundo do jogo, o sistema atualiza a posição espacial dos sons de modo automatizado, conforme os movimentos realizados pelo avatar do jogador, que normalmente é imaginado no centro de tal construção espacial. Neste ponto, é pertinente mencionarmos os aplicativos apelidados de middlewares ${ }^{4}$. Tais ferramentas permitem, ao que nos interessa aqui, configurar parâmetros para o processamento digital de sinal que é desempenhado durante o gameplay processo que opera em segundo plano, gerenciando a performance do áudio. 0 exemplo abaixo (Figura 3) mostra a posição de escuta padrão (esfera vermelha) designada ao jogador na simulação do espaço no jogo Nier: Automata (2017). A partir dela, os eventos sonoros são reorganizados pelo computador

3 I work in television: why should I care about Dolby Atmos?. [S.l.], 2018. Disponível em: <http://www.remotewest.com/the-penseive/>. Acesso: 20 fev. 2020.

4 Se tratam de pacotes de ferramentas e bibliotecas de software para o desenvolvimento de jogos. No caso do game audio, são usadas na implementação do design sonoro dos jogos, permitindo ao designer de som trabalhar com parâmetros de áudio de modo a estabelecer as instruções de desempenho do som no jogo e arranjar as lógicas operacionais que definem as respostas do sistema de áudio à ação do jogador.

Dossiê Crise, Feminismo e Comunicação - https://revistaecopos.eco.ufri.br/

ISSN 2175-8689 - v. 23, n. 3, 2020

DOI: 10.29146/eco-pos.v23i3.27451 
sucessivamente, permitindo estender a ilusão espacial do mundo do jogo a partir da agência do jogador e sua relação com o ambiente sonoro construído.

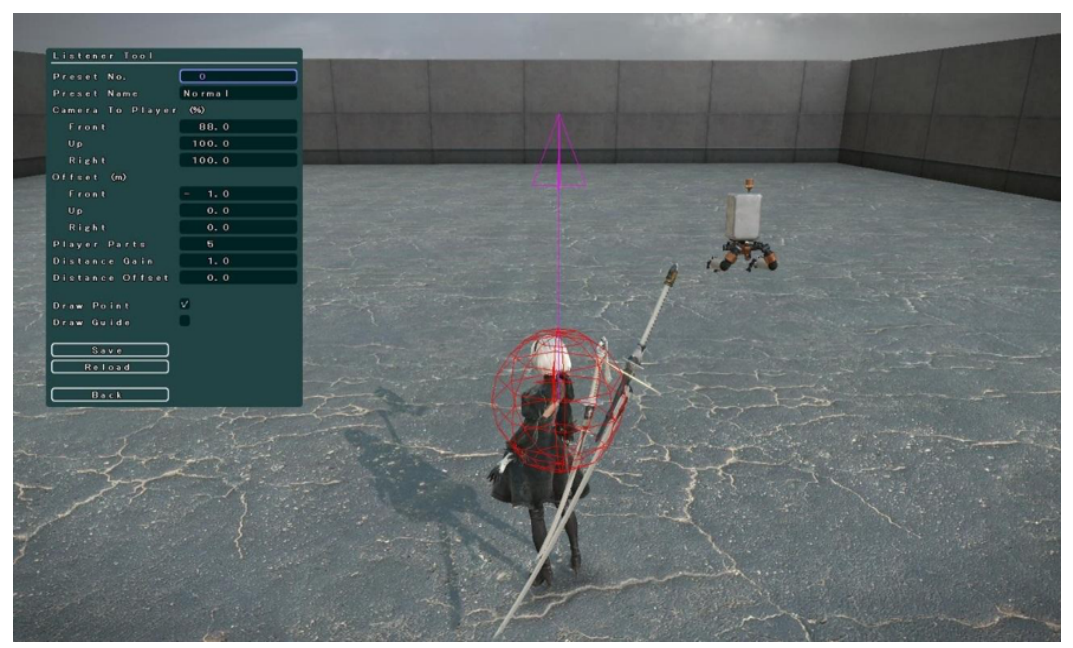

FIG 3: Posição designada ao ouvinte pelo design sonoro de Nier: Automata. Fonte: Audiokinetic Blog 5 .

Ainda na década de 1970, com a proliferação do sistema Dolby aos circuitos de exibição audiovisual, foram ampliadas também as possibilidades de tratamento do espectro de frequências, a eficiência da compressão sonora e o número de pistas de som passíveis de manipulação nos projetos de áudio dos filmes. De acordo com Castanheira e Pereira (2011, p. 137), isto favoreceu o potencial de desenvolvimento de filmes de ação como Star Wars (1977), dentre outras obras de apelo corpóreo mais imediato, adequadas à experiência de sons subgraves (abaixo de $30 \mathrm{~Hz}$ ) e à elaboração sonoplástica complexa. Não nos soa estranho pensar que tais elementos tenham deixado marcas sobre o modo como o som se inscreve como uma interface para mediar a experiência dos jogos digitais, com seus construtos tão dependentes de um sentido de ação no ambiente do jogo. Sobretudo se considerarmos a experiência tátil implicada nos construtos sonoros de determinadas estéticas do cinema (Shaviro, 2015, p.66) que são recorrentemente

\footnotetext{
${ }^{5}$ Disponível em: < https://blog.audiokinetic.com/the-spatial-acoustics-of-nierautomata-and-howwe-used-wwise-to-support-various-forms-of-gameplay-part-1/>. Acesso: 27 fev. 2020.
}

Dossiê Crise, Feminismo e Comunicação - https://revistaecopos.eco.ufrj.br/ 
remodeladas em jogos, reaproveitando sobretudo os efeitos sonoros proporcionados pela seleção de frequências subgraves (em sons de golpes, explosões próximas e efeitos de forte impacto) e ultra altas (tinidos, zumbidos e sibilos muito estridentes, notadamente recorrentes em jogos de tiro em primeira pessoa e em jogos ambientados em narrativas históricas de guerra). Enquanto interfaces sonoras, estes construtos modelam formas-agentes de sincronia tátil e audiovisual, participando ativamente na costura simbólica e material entre o jogador e o aparato na experiência perceptiva do jogo.

\section{0 usuário como eixo gravitacional da dimensão audível nos jogos digitais}

Walter Benjamin já identificava uma experiência de caráter imersivo mesmo nos jogos de azar, afirmando que "o jogar converte o tempo em um narcótico" e que "as fantasmagorias do espaço às quais o flâneur se devota encontram uma contraparte nas fantasmagorias do tempo pelas quais o jogador é viciado" (Benjamin, 2009, p.12). Ele referia-se ao modo como o dispositivo do jogo é capaz de agenciar a experiência temporal do jogador, enfatizando sobretudo o valor de uso do tempo despendido por este. Há, claro, importantes diferenças na sensação da passagem do tempo nos jogos de azar e nos jogos digitais. Enquanto, na descrição benjaminiana do jogo de azar, a condição de expectativa ocupa um papel fundamental sobre o domínio da atenção do jogador, nos jogos digitais, com a participação indelével da máquina sobre o gerenciamento rítmico do gameplay, o engendramento de operações e construções audiovisuais de sincronia mediam a relação de percepção temporal entre jogador e jogo. Os dois casos instauram diferentes precondições da experiência temporal, sendo matizados pelas respectivas ambiências tecnoculturais, encarnando modos próprios de agenciar o tempo nos projetos tecnoestéticos que produzem e nas práticas culturais e sociais a eles relacionados. 
Os estímulos provenientes dos construtos de imersão são absorvidos e organizados pelo jogador na sua experiência do mundo do jogo, incorporados à sua percepção do tempo no gameplay de acordo com uma Gestalt prévia da experiência, constituídas por nossas lembranças audiovisuais dos espaços. As sonoridades trabalham a partir delas para coproduzir os sentidos desta experiência. De acordo com Mark Grimshaw (2016, p.465), nossa percepção auditiva é capaz de experimentalmente formular e imaginar topografias aurais, em um processo de plasticidade adaptativa aos ambientes. Com isso, novos espaços podem ser imaginados e elaborados a partir de condições auditórias simuladas, vivenciadas fenomenologicamente. A sensação de "estar aí" no ambiente do jogo decorre de uma série de condições de experiência de usuário construídas com técnicas que criam o mundo imaginado do jogo, que é completado pelo jogador com base em um repertório de experiências pregressas em constante expansão. Grimshaw desenvolve especialmente sobre duas destas condições técnicas.

Em primeiro lugar, é importante notar que o motor (engine) do jogo, o software composto por uma série de sub-rotinas que agenciam a performance do game, opera também como um sistema de sonificação. Isto significa que é a partir dele que se definem os parâmetros para sonificar as ações e reações do jogador na experiência prática do mundo do jogo. Enquanto aplicativo, o motor organiza, desde o início, o engajamento do jogador no gameplay por meio do som, e é com a resposta do jogador que o som projetado deixa seu estado latente para se realizar sonoramente. De início, o jogador escuta aos sons do ambiente construído; em seguida, os sons criados para representar a ação do próprio jogador é que são ouvidos: ações sonificadas. Tal sonificação do jogador (ou usuário), a conversão de um esquema pré-ordenado de áudio em uma série de ações audiovisuais, é instância decisiva a uma demanda por atenção particular dos jogos digitais. Assim, uma variedade de sonoridades do espaço construído e da ação do jogador passam a conviver temporalmente e, com o andamento do jogo, estas camadas vão sendo dissolvidas na experiência. Perambular no mundo sonoro do jogo, envolver-se 
temporalmente com ele, de modo que seu tempo arraste o nosso, é condição fundamental para a concretização da sensação que se denota, habitualmente, de imersão. Podemos concluir, contudo, que aquilo que as interfaces efetivamente promovem são as condições de possibilidade para a recursividade que caracteriza a experiência do jogador, viabilizando o seu entrelaçamento com o gerenciamento procedimental próprio do aparato computacional.

É importante mencionar também que o jogador é posicionado em um ambiente idealmente esférico (Grimshaw se refere predominantemente a jogos que modelam uma perspectiva em primeira ou terceira pessoa). Mesmo quando o avatar não está visualmente situado em uma posição central, o estímulo sonoro do jogo parece vir igualmente de todas as direções, com a localização do avatar entendida como um centro gravitacional das ações, o que torna a característica iminentemente espacial do som (sua irradiação pública, social) em um acontecimento íntimo e individualmente partilhado com o mundo do jogo. Enquanto a paisagem visual construída faz com que nos "sintamos presentes" naquele mundo, para Grimshaw (2016, p.467), no mundo sonoro do jogo nós "estamos presentes". Com isso, o autor quer expressar que, durante o gameplay, o som do jogo se sobrepõe acusticamente aos demais sons, por uma característica da própria experiência psicoacústica, e tão logo estaríamos colocados "no mesmo lugar". Essa colocação, a nosso ver, deve ser analisada com cuidado, pois ao identificá-la como uma característica eminente da fenomenologia do som (que é propriamente da experiência vivida como um todo), corre-se o risco de deixar passar ao largo como esta sensação de "estar aí" da experiência sonora dos mundos dos jogos não é casual. Antes, ela se efetiva através de uma relação íntima com construtos tecnoestéticos de presença, matizados por condições de interface estabelecidas de modo importante pelo design sonoro do jogo.

A nosso ver, essa sensação é produzida apelando a uma espécie de memória gravitacional, relacionada a como apreendemos e nos relacionamos com os fenômenos sonoros. 0 som é um fenômeno cultural, pelo qual as agências do 
mundo se fazem notar como modulações e diferenças de vibrações entre os corpos que participam de seu movimento. A percepção dos eventos sonoros e nosso engajamento afetivo com eles se dá invariavelmente através de nosso corpo, que media nossa relação com o mundo através de uma dimensão audível que, com efeito, converte os fenômenos em objeto da percepção. Neste sentido, fica claro mais uma vez como o som não é percebido somente por nosso aparelho auditório, mas por nosso corpo todo. Nossa pele, nossos ossos, nervos, músculos e nossas disposições afetivas e psicológicas reagem às vibrações como um todo (Schulze, 2019, p.167). Nele, a memória de nossa experiência pregressa age para construir e reconstruir estes estímulos - em última instância, como coloca Peter Krapp (2011, p.71), o que ouvimos efetivamente é sempre a nossa própria audição. Como a entendemos, a experiência de nosso corpo é lembrada, na construção dos jogos, como esse centro gravitacional em torno do qual giraria um mundo (muito mais largo e, entretanto, inacessível em sua totalidade), e ao qual convergiriam as ações de todos os outros agentes. Uma biopolítica está em ação, portanto, na medida em que um corpo estranho é audiovisualmente reconstruído no interior do jogo, suturado como a figura humanoide do avatar. Humanoide menos pelo aspecto representacional de um humano gráfica e sonoramente imitado, e mais por formular como síntese final um modelo idealmente concebido, baseado em nosso aparato sensorial. A concepção de mundo do jogo é, portanto, produto disso que estamos chamando de uma memória gravitacional do próprio humano e, como tal, é antropocêntrica - desde a sua modelagem inicial da dimensão audível dos espaços que exploramos em um jogo de computador, através de um avatar.

Esse viés antropocêntrico revela a preferência por uma imediatez concreta, que identifica como "familiar" nossa interface sensorial humana, o que acaba por ser constituinte de um design "homofílico" (Reed, 2018): a concretização material da familiaridade é, efetivamente, sustentada por uma inclinação conceitual pelo mesmo. Além disso, entendida aqui enquanto uma problemática inerente ao design, devemos levar em conta que esta é uma predisposição que se torna inscrita

Dossiê Crise, Feminismo e Comunicação - https://revistaecopos.eco.ufrj.br/

ISSN 2175-8689 - v. 23, n. 3, 2020

DOI: 10.29146/eco-pos.v23i3.27451 
no próprio corpo tecnicamente construído. Encarnado em modelos de interface antropomórficas, este viés implica numa regularização metódica e sistemática da semelhança. Além de dar vazão a um chauvinismo antropotécnico que tem sido responsável pelos tipos mais regressivos de desumanização ${ }^{6}$, esta busca recorrente pelo familiar acaba mitigando alternativas tecnoestéticas de desfamiliarização para as interfaces humano-computador. Se a homofilia é a imitação computacional de comportamentos antropológicos, as interfaces poderiam, em outra direção, proporcionar não apenas perspectivas mais diversas antropologicamente. Como Benjamin Bratton (2015) propõe, para isso seria preciso uma abertura ao estranho, em direção à formulações projetuais de interfaces que explorassem, a partir de um xenofilismo, outras formas de autonomia estética da máquina, sem o receio de deslocar experimentalmente os agentes humanos do centro subjetivo da sua forma de operação.

\section{As sonoridades dos periféricos e dispositivos auxiliares}

Precisamos estar atentos, portanto, à uniformidade que uma perspectiva imprimiria se considerássemos as interfaces como mediadoras materiais das experiências de jogo, exclusivamente a partir de modelos imitativos de faculdades perceptivas humanas. Outras formas de interfaceamento podem ser percebidas no design sonoro dos jogos digitais, embora as percebamos também calcadas em modelos imediatamente reconhecíveis.

\footnotetext{
6 Já é bastante conhecido o modo como as interfaces gráficas e sonoras, além de outros artefatos técnicos contemporâneos, tendem a privilegiar determinados corpos - para além da visão e escuta computacional, como a inteligência artificial. Do monitoramento seletivo de zonas urbanas políticoeconomicamente marginalizadas por meio de escuta computacional, passando por sistemas de vigilância com vieses xenofóbicos até, no caso mais específico das interfaces de que falamos, a modelagem representacional de determinados corpos em detrimento de outros. 0 modelo de escuta das interfaces sonoras baseadas em representações espaciais tridimensionais, por exemplo, considera como ponto de partida que uma capacidade auditiva regular deve partir de um modelo de escuta binaural. A computação não está dissociada das matrizes de pensamento, ideologias e formas de conhecimento de nossa vida cotidiana e está, pelo contrário, atravessada por elas.
}

Dossiê Crise, Feminismo e Comunicação - https://revistaecopos.eco.ufrj.br/

ISSN 2175-8689 - v. 23, n. 3, 2020

DOI: 10.29146/eco-pos.v23i3.27451 
Jogos do gênero de plataforma, por exemplo, costumam apresentar interfaces que não apontam em direção à imersão e nem à verossimilhança dos espaços sonoros construídos. Uma característica comum entre jogos deste tipo é que, assim como a interface gráfica apresenta a movimentação das personagens em movimentos paralelos e diagonais, em uma perspectiva achatada e plana, o interfaceamento sonoro também expressa outra tendência estética predominante: não só os eventos sonoros deixam de ser representados sob uma perspectiva espacial esférica, como passamos a perceber também a presença muito menos moderada de repetição dos mesmos sons, de trilhas de fundo com loops explícitos e constantes ao longo da experiência, de uma dinâmica de mixagem mais uniforme e, de modo geral, bastante cacofônica. Este tipo de construção expressa a marca de outra natureza estética, pelas enunciações de derrota e vitória que remontam, antes, aos interfaceamentos sonoros propostos por máquinas caça-níqueis, jogos de pinball e aparelhos para divertimento ligeiro, apelando mais claramente a desafios de agilidade motora. Suas sonoridades parecem emular os estímulos que compõem jogos de reflexos e brinquedos mecânicos de ação e resposta, exigindo que a interface sonora basicamente repita feedbacks sonoros consecutivos a cada ação, produzindo efeitos sucessivos de hipérbole que pontuam as ações performadas entre jogador e máquina.

De tal modo, estes modelos remetem à dimensão audível de aparelhos mecânicos de entretenimento, cujo modo de operação era bastante dependente de uma gramática estabelecida pelos sons. Como no caso de uma máquina de caçaníqueis mecânica: antes da eletrônica permitir sincronizar às imagens dos slots na máquina o som de uma moeda repinicando em um recipiente, era o som do contato da própria moeda caindo em uma vasilha metálica, chocando-se com outras moedas, que sinalizava sonoramente o resultado do jogo ao apostador.

O jogo Pong (1972), enquanto primeiro jogo de fliperama lucrativo, é emblemático desta passagem. Claus Pias (2004) escreve que como a máquina deveria ser acomodada em bares e salas de espera, Pong foi elaborado como um 
jogo a ser operado por um jogador solitário contra a máquina, sem um oponente humano. Para isso, foi necessário inventar tanto "um início, para permitir que pudesse ser inserida uma moeda", como "um fim, para exigir a inserção de outras moedas" (Pias, 2004, p.128). As interfaces para operar máquinas de jogar, entretanto, podem ser relacionadas a toda uma rede que inclui aparelhos operados por moedas, como as jukeboxes, dentre outras máquinas de apostas, slots, pinball, etc. Karen Collins (2016) explica que, nos Estados Unidos, ainda durante a Era da Proibição (1920-1933), as iniciativas de inserir som eletromecânico nas máquinas de jogo (ilegais) se deram como uma forma de passá-las por máquinas de música (legalizadas), de modo que pudessem ser comercializadas. As máquinas eletromecânicas de jogar, naquele momento, tocavam apenas uma música de fundo em loop, enquanto o fluxo do jogo era pontuado pelos sons dos próprios materiais do aparelho e do ambiente em que se jogava. A maturação das gramáticas indicativas de começo e de fim do jogo, bem como a sugestão de emoções específicas por meio de climas musicais, foram fruto de uma série de polinizações cruzadas entre as interfaces destas máquinas com outras formas culturais. Os códigos sonoros foram inventados gradualmente, em negociação com um ambiente tecnocultural emergente, de modo a elaborar os efeitos de relação que caracterizam as interfaces dos jogos eletromecânicos. As construções metafísicas de pontuação, bônus, continuidade e interrupção - todos os sentidos que apreendemos e que, entre o começo e o fim do jogo, produzem a sensação de engajamento com a máquina -, tiveram de ser elaboradas audiovisualmente para promover condições emergentes de mediação.

Os jogos digitais realizam interfaceamentos a partir de todo um programa de associações sincrônicas entre as ações performadas pelo jogador e os sons disparados simultaneamente pela máquina. No jogo Cuphead (2017), por exemplo, a enunciação de triunfo é produzida pelo som de moedas repinicando e de uma caixa registradora, enquanto se contabilizam os pontos do jogador, e uma memória destas máquinas é atualizada implicitamente. 0 efeito do tilintar brilhante de uma

Dossiê Crise, Feminismo e Comunicação - https://revistaecopos.eco.ufrj.br/

ISSN 2175-8689 - v. 23, n. 3, 2020

DOI: 10.29146/eco-pos.v23i3.27451 
moeda, que remete ao contato de sua superfície metálica com algum outro tipo de metal (ou mesmo com outras moedas), é claramente estendido a outros jogos. 0 timbre brilhante que ouvimos é sobressalente em jogos clássicos de plataforma ${ }^{7}$, mas não é exclusivo a eles, e é interessante como mesmo em games que pressupõem pôr em relação jogador e jogo por meio de outras estéticas, apelando a indícios sonoros de outros materiais, parecem conter em si traços destas enunciações. Isso se mostra especialmente em menus de configuração. Mesmo ao recorrer a sonoridades mais abstratas, é notável como em menus de configuração de jogos contemporâneos os sons mais brilhantes e estridentes são sincronizados recorrentemente com ações afirmativas e de confirmação.

A dimensão audível destes elementos aparentemente triviais dos jogos nos dá acesso a todo um mundo de elementos que ligam as interfaces sonoras dos games contemporâneos a sentidos amplamente disseminados na tecnocultura. Ela dá a ouvir gramáticas gradualmente amadurecidas como metáforas para algumas das mais importantes enunciações dos jogos: os sentidos de vitória e derrota, sucesso e fracasso, progresso e interrupção, gratificação e punição.

Há uma série de clichês reproduzidos, sobretudo em jogos de tiro em primeira pessoa, para pontuar sonoramente o fracasso do jogador. Em Spec Ops: The Line (2012), por exemplo, à medida em que o jogador sofre mais ataques, ele passa a ouvir de modo diferente a todos os elementos que o circundam no ambiente do jogo. Alguns sons que eram ouvidos começam a desaparecer e, efetivamente, toda uma gama de frequências do espectro de áudio é suprimida, com os objetos sonoros soando todos abafados, a partir daí. São suprimidas, sobretudo, as frequências altas e médio-altas, o que emula seletivamente uma perda súbita de audição. 0 jogador vai sendo "punido" pelo seu mau desempenho com a perda de sentidos do avatar modelado no mundo do jogo. Enunciativamente, a relação entre o corpo do jogador e o do avatar vai sendo sensorialmente

7 Sonic: The Hedgehog (1991), Super Mario World (1990), Rayman (1995), para citar alguns exemplos.

Dossiê Crise, Feminismo e Comunicação - https://revistaecopos.eco.ufrj.br/

ISSN 2175-8689 - v. 23, n. 3, 2020

DOI: 10.29146/eco-pos.v23i3.27451 
descosturada. Este efeito é audiovisual, na medida que, em sincronia com a filtragem do áudio, não só a tela vai ficando poluída de vermelho como o restante da paisagem de fundo vai ganhando um aspecto monocromático, perdendo sua saturação, mergulhada em tons de cinza. Ou seja, é construída uma correlação entre cor e som para corresponder ao efeito de derrota iminente do jogador, dramatizando a morte banal do protagonista no jogo. Quando enfim o jogador é derrotado, além dos efeitos referidos, os sons provenientes da diegese do jogo vão se decompondo, sendo desacelerados, ralentando, até um esperado silêncio.

\section{Automações do audível: efeitos de controle}

Estes exemplos sugerem que o design sonoro habitualmente exerce a tarefa de "domar" os ruídos do ambiente, de modo a convertê-los em elementos de interface entre o humano e o computador. Conforme Stefan Höltgen (2018), os computadores sempre foram ruidosos, produzindo barulhos diversos a partir de motores internos ou anexos movimentados (impressoras, scanners, unidades de fita), rotores (em ventoinhas e ventiladores), unidades de gravação móveis (disquetes) ou eletromagnéticas (discos rígidos) e interruptores eletromecânicos (relés nas fontes de alimentação). Do ponto de vista operacional, a experiência dos jogos subentende um programa jogável, em que o input de um usuário e as respostas programadas são mediadas por interfaces gráficas e sonoras de usuário, mas também por dispositivos periféricos como mouses, teclados, joysticks, controladores, monitores e alto-falantes.

Pensemos, por um instante, no clique de um mouse. Uma breve arqueoacústica do clique talvez permita fazer um movimento da figura ao fundo, visto que os mouses associaram uma série de gestos a sonoridades, codificando-os. Para ficarmos com exemplos mais básicos: um clique - selecionar; dois cliques entrar/abrir; a própria onomatopeia - “click!". No entanto, mais profundamente do que estes "avisos" sonoros, há uma segunda camada: o clique do mouse não 
sinaliza ao usuário apenas sentidos semânticos. Ele também sinaliza que o botão já foi apertado o suficiente. Em média, tanto mouses quanto teclados são projetados para, mediante pressão, disparar o som (de clicar e teclar) quando cerca de $50 \%$ da pressão máxima possível do botão for exercida. Isso se deve ao grande número de botões e teclas que pressionamos cotidianamente em periféricos como estes, e se trata de uma aplicação do design para minimizar a fadiga muscular e as lesões por esforço repetitivo. 0 som de clicar, neste caso, além de cumprir uma função semântica, é um sinal sonoro que trabalha em razão da ergonomia, tanto para tornar mais efetivo o uso do computador, como para não desestimular o seu uso prolongado.

Nos jogos contemporâneos, sobretudo em seus menus de configuração, também é curioso como o clique é utilizado recorrentemente enquanto reperformatização semântica. Sua função semântica é rememorada ao realizarmos ações através do controlador para efetuar operações de escolha na tela, em jogos dos formatos mais variados. Dispara-se a imitação do som do clique de um mouse, como se precisássemos desta segunda confirmação para apreender seu sentido ${ }^{8}$. 0 jogo aparenta ignorar, portanto, o clique realizado no controlador, o que é bastante revelador. Incorporando-o à própria ação do jogador, o game trabalha para eliminar, ou ao menos encobrir de alguma forma, os signos sonoros que ligam o jogador diretamente à locação em que ele joga - e para isso estão aí os periféricos informáticos atuais, notadamente menos barulhentos que seus precedentes (basta compararmos o ruído moderado do controlador de um Microsoft X-Box contemporâneo aos rangidos e estalos inerentes ao se jogar em um Atari 2600 da década de 1970). Tal solução também é projetual. A parte da experiência do jogo que se refere ao barulho prosaico do local em que se joga, aos ruídos do hardware, às conversas laterais, ao ranger dos botões sendo esmagados -, tende a ser (ao

\footnotetext{
8 É interessante notar como essa persistência do clique se mostra como uma escolha culturalmente disseminada, associada a diferentes softwares e hardwares. 0 clique das câmeras amadoras digitais e dos softwares fotográficos para smartphones, imitando o ruído do obturador de uma câmera analógica, rememora como um rito kitsch o gesto de fotografar, de uma maneira semelhante.
}

Dossiê Crise, Feminismo e Comunicação - https://revistaecopos.eco.ufrj.br/ 
menos idealmente) silenciada, na tentativa de produzir uma atmosfera potencialmente mais envolvente e menos dispersiva, favorecendo a escuta dos sons projetualmente designados ao mundo do jogo.

Um tipo de interface particularmente importante, que remete à dimensão audível, refere-se aos softwares para gerir alterações dinâmicas do áudio durante o gameplay. Com eles, desenvolvedores e designers de som podem escrever uma espécie de roteiro de feedbacks sonoros para corresponder às microdecisões do jogador, na tentativa de reduzir o espaço de indeterminação entre jogador e máquina através de uma interface sonora responsiva. Este tipo de projeto torna audível, na própria performance do jogo, a ação de uma tendência tecnoestética importante na contemporaneidade, de tornar o regime de uso de aparelhos mais assimilável ao usuário, através das interfaces computacionais.

Neste aspecto, um caso exemplar é o sistema iMUSE (Interactive Music Streaming Engine). Desenvolvido pela LucasArts no início da década de 1990, ele pode ser entendido como o modelo prototípico de grande parte dos complexos sistemas de áudio presentes nos jogos contemporâneos. Sendo utilizado nos jogos point-and-click da LucasArts ${ }^{9}$, e servindo como inspiração para o desenvolvimento de outros sistemas de áudio para games posteriores, o iMUSE possibilitou ao compositor criar transições e mudanças de estado na música em reação a eventos, situações e trechos acessados pelo jogador no interior do jogo. Passou a ser possível realizar mudanças de andamento, instrumentação, intensidade, tonalidade, dentre outras, além de programar saltos e loops para trechos específicos da trilha, como indicado pelas linhas de comando listadas na imagem a seguir.

9 Desenvolvido primeiramente para o jogo Monkey Island 2: Le Chuck's Revenge (1991), o iMUSE passou a ser usado nos jogos deste gênero desenvolvidos pela empresa desde então.

Dossiê Crise, Feminismo e Comunicação - https://revistaecopos.eco.ufrj.br/ 
TABLE 3

MIDI COMMANDS

md_set_priority (sound, priority)

md_set_vol (sound, vol)

md_set__pan (sound, pan)

md_set_transpose (sound, rel_flag, transpose)

md_set_detune (sound, detune)

md_set_speed (sound, speed)

md_jump (sound, chunk, beat, tick)

md_scan (sound, chunk, beat, tick)

md_set_loop (sound, count, start_beat, start_tick,

end_beat, end_tick)

md_clear_loop (sound)

md_set_part_enable (sound, chan, state)

md_set_part_vol (sound, chan, vol)

md_set_hook (sound, class, val, chan)

md_fade_vol (sound number, vol, time)

md_enqueue_trigger (sound, marker_id)

md_enqueue_command (param1 ..., param7)

md_clear_queue ( )

md_query_queue (param)

FIG. 4: Instruções programáveis para a música no iMUSE. Fonte: Google APIs.

Este sistema torna perceptível, assim, o modo particular como os jogos digitais atualizam tendências audiovisuais de construção de sincronismo emocional ${ }^{10}$. 0 iMUSE mostra como o processo computacional permite que os protocolos de controle do áudio e a performance do som operem separadamente. Informações de cadência, altura, duração, dentre outros parâmetros musicais, enfim, tudo isso pode ser transposto modularmente, precisamente em razão da constituição material desta interface. A funcionalidade do iMUSE deixa evidente o assincronismo infraestrutural endêmico da comunicação digital, que é reiteradamente velado através dos construtos audiovisuais de sincronia propelidos nas mídias digitais. Pela separação conceitual e material entre software e hardware, a arquitetura do computador estabelece um regime de operação propriamente assíncrono, condição que está intimamente ligada à qualidade da experiência fenomenológica de uso das mídias derivadas da computação.

A experiência de sincronia estrita, apresentada nos jogos que utilizam efeitos de processamento digital de sinal (PDS) para gerar variabilidade interna nos efeitos

10 Tendências que não são exclusivas a eles, porém. Talvez possamos situar, como suas precursoras históricas, as partituras com instruções enviadas aos pianistas empregados pelas salas de exibição do chamado "primeiro cinema" (Davies, 1999, p.17).

Dossiê Crise, Feminismo e Comunicação - https://revistaecopos.eco.ufrj.br/

ISSN 2175-8689 - v. 23, n. 3, 2020

DOI: 10.29146/eco-pos.v23i3.27451 
sonoros dos jogos é, portanto, paradoxal. Mais precisamente, sistemas como este permitem associar música e sons à sensação de controle, característica por sua vez essencial a uma interface imaginada como produtora de efeitos de manipulação direta no interior dos mundos dos jogos. 0 projeto do iMUSE torna aparente alguns dos desejos associados ao design de jogos, estando estes incorporados à técnica. 0 anseio de produzir uma sensação de controle, através da sincronização, fica evidente em diversos trechos do texto da patente registrada deste sistema:

É fácil notar porque o fluxo musical fica comprometido, quando se requer à música mudar de um trecho a outro nos sistemas de entretenimento computacionais existentes. Por exemplo, suponha uma enérgica cena de luta no jogo, que pode terminar subitamente em vitória ou em derrota. Nos sistemas existentes haveria provavelmente três trechos musicais: uma música de luta (em loop), uma música de vitória e uma música de derrota. Ao acabar a luta, a música de luta se encerra, iniciando a música de vitória ou a de derrota. A passagem ocorre sem levar em conta o que está acontecendo na música de luta antes do momento da transição. Perde-se qualquer pico de emoção ou sensação de fluxo que se tenha estabelecido, e a troca soa abrupta e antinatural. [...] Logo, os sistemas musicais atuais não garantem ao sistema de entretenimento a habilidade de informar ao sistema musical como responder inteligente e artisticamente aos eventos e ações do jogo. É necessário que a música e os efeitos sonoros possam ser incluídos em um sistema de som controlado pelo computador, capaz de criar composições musicais naturais e apropriadas que se alterem dinamicamente com os eventos e ações do jogo, em resposta aos comandos do sistema sonoro (Land; McConell, 1991, p.22).

Deriva-se disso a elaboração de ambientes sonoros ditos mais "naturais" ao jogador, ou seja, ajustando terminologicamente este enunciado: que atuem em oposição à experiência estruturalmente assíncrona do audiovisual no jogo. A qualidade de um design sonoro que aparente naturalidade corresponde, portanto, à capacidade de produzir uma sensação sempre mais atualizada de controle no interior do jogo. 0 êxito em realizar este efeito depende de uma maior quantificação de estados associados a ações do jogador no sistema sonoro construído. Ou seja, a sensação de sincronismo entre ações e respostas aumenta à medida que o design sonoro do jogo faz uma previsão, divisão e programação mais decomposta de cada ação do jogador, dentro de um certo horizonte de

Dossiê Crise, Feminismo e Comunicação - https://revistaecopos.eco.ufri.br/

ISSN 2175-8689 - v. 23, n. 3, 2020

DOI: 10.29146/eco-pos.v23i3.27451 
possibilidades de tal sistema. Na patente do iMUSE sobressai, ainda, a noção mais clara do que os desenvolvedores do sistema entendem por um sistema inteligente: aquele capaz de promover uma reação mais fracionada entre os gestos realizados pelo jogador e as mudanças de estado no som do jogo, de modo a tornar a performance da máquina - e, com ela, a própria interface entre humano e computar - tão opaca quanto for possível.

\section{Interfaces culturais e os ofícios da percepção}

Conforme Manovich (2001, p.118), em função das operações básicas do computador aplicarem-se às mais distintas formas culturais, estas passam a partilhar uma série de processos em comum: copiar, recortar, colar; classificar, procurar, filtrar; transcodificar, ripar, mixar. Como estas operações, as características de sistemas como o iMUSE também mostram algumas qualidades elementares que se estendem para além da música dos jogos: a impressão de se realizar ações em "tempo real", a estética operativa que devém da sensação de se controlar os objetos de interesse na tela; mas também o forte desejo de se esconder os loops, as quebras bruscas de andamento, os assincronismos da máquina e as operações mecânicas mais elementares que são inerentes ao seu uso. Estas formas se estendem para além das operações cotidianas com dados computacionais (seguramente, podemos dizer que também ultrapassam sua funcionalidade nos jogos), dispersando-se na vida cotidiana enquanto modos de pensar, trabalhar e existir atualmente.

As formas de projetar a dimensão audível dos jogos são correspondentes a uma Gestalt de outros artefatos "responsivos" contemporâneos, utilizados em performances artísticas interativas, em simulações binaurais de ambientes acústicos ou mesmo em sistemas assistentes de voz em aparelhos móveis ou domésticos. A apropriação destas construções sonoras em direção a formas potencialmente imersivas responde mais amplamente a uma cultura disposta a

\section{Dossiê Crise, Feminismo e Comunicação - https://revistaecopos.eco.ufrj.br/}

ISSN 2175-8689 - v. 23, n. 3, 2020

DOI: 10.29146/eco-pos.v23i3.27451 
conectar-se e desconectar-se através de aparelhos personalizados. À medida que o computador (em distintas dimensões e formatos) se propele a uma ampla variedade de atividades da vida social, o desenvolvimento de interfaces gráficas e sonoras familiarizáveis e "adaptáveis" torna-se essencial para o relacionamento prosaico do humano com a máquina. As lembranças de construtos audiovisuais pregressos e de hábitos de mídia coletivos e individuais, portanto, sobrepõem-se nos projetos de interface contemporâneos.

A metáfora da interface, assim, nos parece bastante útil para perscrutarmos as condições materiais das sonoridades nos jogos digitais, mas também fora deles. Pelas condições de experiência que ofertam através dos jogos, tais interfaces agem como uma forma de ambientar os jogadores às lógicas, estruturas, regimes, gestos e hábitos motores das rotinas de uso de máquinas diversas. Para David Parisi:

[...] as interfaces dos jogos - enquanto espaços através dos quais o humano acopla-se à máquina - cumprem uma função biopolítica, permitindo a captura de dados sobre o corpo do jogador, quantificando em microescala as temporalidades dos processos sensório-motores humanos, aproveitando os ritmos da interação com a máquina. As interfaces dos jogos tornam produtivos os corpos e processos corporais dos jogadores nos estágios do capitalismo tardio e do neoliberalismo, que dependem da circulação de dados através de sujeitos processadores de informação (Parisi, 2017, p.7).

Neste sentido, as interfaces sonoras dos jogos também emergem como manifestações materiais da tecnocultura contemporânea. A elas correspondem os ambientes potencialmente imersivos e responsivos construídos pelos jogos, que por sua vez retroalimentam a cultura pela recodificação de estéticas lembradas do audiovisual sob diferentes condições técnicas. Assim, as interfaces sonoras manifestam as tensões entre as lógicas industriais e pós-industriais que coabitam a sociedade contemporânea. Nestes tensionamentos, ganha centralidade o processamento individual de informações sonoras e visuais presente em atividades cotidianas, das quais o sujeito depende para relacionar-se com o amplo contingente informacional disperso contemporaneamente.

Dossiê Crise, Feminismo e Comunicação - https://revistaecopos.eco.ufrj.br/ 
As construções de interfaces sonoras fazem parte do compósito pelo qual interpela-se o corpo - convertido em usuário, através de aparelhos - na condição contemporânea da tecnocultura. Nesta, o humano cumpre um papel laboral cotidiano de monitoramento e regulação do fluxo de informações (Manovich, 1996, p.7), observando displays, analisando dados recebidos, tomando decisões e operando controladores - tarefas que correspondem às funções cognitivas da percepção ligadas à atenção, à associatividade e à resolução de problemas. Nesta direção, a automação das sonoridades e o seu uso para produzir sentidos de controle, conduzem a uma hibridização entre o trabalho maquinal e o semiótico, por meio de atividades ocupadas primariamente com o viés operativo de um conjunto de signos visuais e sonoros.

Há, portanto, um fundo tecnocultural que liga materialmente as sonoridades dos jogos digitais à história do design de usabilidade, particularmente no que se refere ao estudo da economia de movimentos (ergonomia) e da produção de condições técnicas de interfaceamento propostas pelos artefatos computacionais. Estas permitem projetar um aparato capaz de delegar responsabilidades de operação ao usuário, o co-criando como jogador. Trata-se do esforço de "compatibilização" de que fala Claus Pias (2011, p.180), pelo qual é agenciado um processo de sutura entre o corpo humano e a lógica da máquina, através de suas condições de uso: o computador é "humanizado" através da codificação de linguagem simbólica, enquanto o humano é moldado às condições de agência da máquina, por meio da conformação dos seus movimentos corporais aos limites de operabilidade a partir do uso do aparato computacional. Para operar as máquinas, é necessário ao humano apreender as suas estruturas, lógicas e gestualidades, em um processo de subjetivação maquínica realizado por meio de uma proto-interação simbólica e corporal. No interior do game, não conseguindo apreender a estrutura ou "passar" neste teste de compatibilidade, o jogador pode ser impedido de prosseguir no jogo, sendo punido com uma morte simbólica. 


\section{Considerações finais}

Podemos concluir, após realizarmos um movimento arqueogenealógico sobre as interfaces sonoras dos jogos digitais, que os interfaceamentos computacionais não tomam o lugar do aparato audiovisual pregresso. Antes, eles incorporam traços de sua linguagem, expressando algo do que já foram, por um lado, mas também estendendo estas gramáticas para diferentes usos e sentidos, ao sabor das contingências de uma ambiência tecnocultural em constante remodelagem. Estéticas pregressas se articulam com as técnicas advindas da informática, em importante medida, através das interfaces humano-computador. A partir do aparato material que dá forma à sua dimensão audível, os jogos também constroem sentidos pela sincronização de sons a ações pré-condicionadas por design, tornando ambientes computacionais utilizáveis a usuários que também encontram seu lugar matizado pelos efeitos de relação com estes espaços. Por meio de interfaces que mediam a experiência destes usuários, a dimensão audível é mobilizada para imaginá-los no interior da própria mídia.

Considerando as lógicas operacionais que elencamos ao longo deste trabalho, podemos também nos perguntar como tais interfaceamentos humanocomputador operam sobre as economias da atenção dispersas na tecnocultura através da construção de seu aparato tecnoestético. Esta é uma das dimensões que permitem aproximar, sob o aspecto da usabilidade, a experiência de quem opera um jogo no computador muito mais da sensorialidade daquele que utiliza outros artefatos técnicos da cultura digital, do que da experiência sensível do jogador de cartas, de jogos de tabuleiros, dentre outras formas pré-digitais de jogar. A usabilidade informática, nestes casos, é partilhada como uma precondição material peculiar a esta forma de comunicação. Reside aí, sobretudo, mais uma razão para seguir interrogando as formas e estéticas dos jogos digitais, muito significativas em 
uma ecologia de mídias que viabilizam uma atenção 24/7 de seus usuários e que multiplicam, através de interfaces culturais, as formas de uso do audiovisual no presente.

\section{Referências bibliográficas:}

BENJAMIN, Walter. Passagens. Belo Horizonte: UFMG, 2009.

BOGOST, Ian. How to talk about videogames. Minneapolis: University of Minnesota, 2015.

BOLTER, Jay; GROMALA, Diane. Windows and mirrors: interaction design, digital art and the myth of transparency. Cambridge: MIT, 2003.

BRATTON, Benjamin. The stack: on software and sovereignty. Cambridge: MIT Press, 2015.

CARDOSO, Rafael. Design para um mundo complexo. São Paulo: Cosac Naify, 2016.

CASTANHEIRA, José C. O som eletrônico no cinema: uma abordagem fenomenológica. In: Contemporânea, Rio de Janeiro, 2010, v. 8, n. 2, pp. 108-119.

CASTANHEIRA, José C.; PEREIRA, Vinicius A. Mais grave! Como as tecnologias midiáticas afetam as sensorialidades auditivas $\mathrm{e}$ os códigos sonoros contemporâneos. In: Contracampo, Niterói, 2011, n. 23, pp. 130-143.

COLLINS, Karen. Game sound in the mechanical arcades: an audio archaeology. In: Game studies: the international journal of computer game research, Copenhagen, v.16, n.1, 2016.

DAVIES, Richard. Complete guide to film scoring. Boston: Berklee, 1999.

Dossiê Crise, Feminismo e Comunicação - https://revistaecopos.eco.ufrj.br/

ISSN 2175-8689 - v. 23, n. 3, 2020

DOI: $10.29146 /$ eco-pos.v23i3.27451 
FELINTO, Erick. Em busca do tempo perdido. 0 sequestro da história na cibercultura e os desafios da teoria da mídia. In: MATRIZes, São Paulo, 2011, v. 4, n. 2.

FISCHER, Gustavo. Cinema em devir nos games: por um olhar arque-genealógico nas interfaces culturais. In: GERBASE, Carlos; GUTFRIEND, Cristiane Freitas (org.). Cinema em choque: diálogos e rupturas. Porto Alegre: Sulina, 2013.

FISCHER, Gustavo D. Desencavando interfaces: reflexões sobre arqueologia da mídia e procedimentos de resgate de páginas web. In: STEFEN, Cezar; BENVENUTO, Álvaro. (Orgs.). Tecnologia pra quê? As reconfigurações no campo da Comunicação Social. Porto Alegre: Armazém Digital, 2012.

GALLOWAY, Alexander. The unworkable interface. In: New literary history. Charlottesville, v.39, n.4, 2008.

GRIMSHAW, Mark. The privatization of sound space. In: COBUSSEN, M.; MEELBERT, V.; TRUAX, B. (org.). The Routledge companion to sounding art. Nova York: Taylor \& Francis, 2016.

GUINS, Raiford. After life history: an interview with Raiford Guins on his Game After: a cultural study of video game afterlife. In: Reconstruction, Zurique, v.14, n.1, 2014.

New... now?. Or why a design history of coin-op video game. In: American Journal of Play, Rochester, v. 10, n.1, 2017.

HÖLTGEN, Stefan. Play that pokey music: computer archeological gaming with vintage sound chips. In: The computer games journal, v. 7, n. 4, 2018, pp. 213-230.

HUHTAMO, Erkki. Slots of fun, slots of trouble: toward an archaeology of electronic gaming. In: RAESSENS, Joost; GOLDSTEIN, Jeffrey. Handbook of computer games studies. Cambridge: MIT, 2005. 
HUHTAMO, Erkki; PARIKKA, Jussi. Media archaeology: approaches, applications, and implications. Berkeley: University of California, 2011.

KOHATA, Shuji; SHINDO, Misaki. The spatial acoustics of Nier: Automata. In: Blog Audiokinetic. Montreal, 4 dez. 2018. Disponível: https://blog.audiokinetic.com/thespatial-acoustics-of-nierautomata-and-how-we-used-wwise-to-support-variousforms-of-gameplay-part-1/. Acesso: 16 jul. 2019.

KRAPP, Peter. Noise channels: glitch and error in digital culture. Minneapolis: Minnesota University, 2011.

LAND, Michael; MCCONNELL, Peter. Method and apparatus for dynamically composing music and sound effects using a computer entertainment system. Google Patents. LucasArts Entertainment, 1991.

MANOVICH, Lev. Language of new media. Cambridge: MIT, 2001.

. The Labor of Perception. In: LEESON, Lynn Hershman (Ed.). Clicking in: hot links to a digital culture. Seattle: Bay, 1996.

PARISI, David. Game interfaces as disabling infrastructures. In: Analog game studies, Pittsburgh, n.3, v.4, 2017.

PIAS, Claus. Action, adventure, desire. In: HAGEBÖLLING, Heide (org.). Interactive dramaturgies: new approaches in multimedia content and design. Berlin: Springer, 2004.

The game player's duty: the user as the gestalt of ports. In: HUHTAMO, Erkki; PARIKKA, Jussi. Media archaeology: approaches, applications and implications. Berkeley: University of California, 2011. 
REED, Patricia. Xenofilia e desnaturalização computacional. São Paulo: Zazie Edições, 2018.

SCHULZE, Holger. Sound works: a cultural theory of sound design. New York: Bloomsbury, 2019.

SHAVIRO, Steven. O corpo cinemático. São Paulo: Paulus, 2015.

STERNE, Jonathan. The sound studies reader. New York: Routledge, 2012. 